\title{
Cholesteryl Ester Transfer Protein Gene Polymorphisms and Longevity Syndrome
}

\author{
Genovefa Kolovou $^{1, *}$, Marianna Stamatelatou ${ }^{1}$, Katherine Anagnostopoulou ${ }^{1}$, Peggy Kostakou ${ }^{1}$, \\ Vana Kolovou ${ }^{1}$, Constantinos Mihas ${ }^{2}$, Ioannis Vasiliadis ${ }^{1}$, Olga Diakoumakou ${ }^{1}$, \\ Dimitri P Mikhailidis ${ }^{3}$ and Dennis V Cokkinos ${ }^{1}$ \\ ${ }^{1} 1^{\text {st }}$ Cardiology Department, Onassis Cardiac Surgery Center Athens, Greece \\ ${ }^{2}$ Internal Medicine Department, General Hospital of Kimi, Kimi, Greece \\ ${ }^{3}$ Department of Clinical Biochemistry (Vascular Prevention Clinic), Royal Free campus, University College London \\ Medical School, University College London (UCL), London, UK
}

\begin{abstract}
Purpose: High levels of high density lipoprotein (HDL) cholesterol are associated with a decreased risk of coronary heart disease (CHD). Subjects with high levels of HDL cholesterol ( $>70 \mathrm{mg} / \mathrm{dl} ; 1.79 \mathrm{mmol} / \mathrm{l})$ as well as high levels of low density lipoprotein (LDL) cholesterol, could represent a group with longevity syndrome (LS). Since HDL particles are influenced by cholesteryl ester transfer protein (CETP) activity, it is worth studying the CETP polymorphism. The aim of the study was to detect whether 2 genetic variants of the CETP are associated with the LS.

Subjects and Methods: The study population consisted of 136 unrelated men and women with no personal and family history of CHD; 69 met the criteria for LS and 67 did not meet these criteria and had "normal" HDL cholesterol ( $>40$ and $<70 \mathrm{mg} / \mathrm{dl} ;>1.03$ and $<1.79 \mathrm{mmol} / \mathrm{l})$. All patients were genotyped for the TaqIB and I405V polymorphisms.

Results: The B2 allele frequency of TaqIB polymorphism was higher in the LS in comparison with the non-LS group $(\mathrm{p}=0.03)$ whereas B1 allele frequency was higher in the non-LS group $(\mathrm{p}=0.03)$.

Conclusions: Gene polymorphisms could help decide whether individuals who have increased levels of both LDL cholesterol and HDL cholesterol require treatment. Some of the prerequisites could include that subjects with LS should not only have very high levels of HDL cholesterol but also favorable gene polymorphisms. However, further investigations with a larger sample and including other gene polymorphisms, are needed.
\end{abstract}

Keywords: Coronary heart disease, high density lipoprotein-cholesterol, longevity syndrome, TaqIB and I405V polymorphisms.

\section{INTRODUCTION}

The hypothesis that low high density lipoprotein (HDL) cholesterol concentrations are associated with a greater risk of coronary heart disease (CHD) has been raised since the 1950s [1]. More than 50 years on, following a number of prospective studies [2-7], HDL cholesterol is now established as an independent risk factor for CHD [8]. However, there may also be a positive association of HDL cholesterol levels with increased CHD risk [9].

Based on clinical evidence that elevated HDL cholesterol levels reduce CHD risk it is plausible that this characteristic could also be associated with longer life expectancy [10]. This hypothesis is further supported by the fact that high HDL cholesterol levels are often observed in healthy elderly persons aged $>85$ years $[10,11]$. The levels of HDL cholesterol are influenced by various environmental and genetic

*Address correspondence to this author at the Onassis Cardiac Surgery Center, 356 Sygrou Ave 17674 Athens, Greece; Tel: +30 210 9493520; Fax: +30 210 9493336; E-mail: genovefa@kolovou.com factors. Family and twin studies have estimated that the heritability of HDL cholesterol levels varies from 35 to $66 \%$ [10, $12,13]$. A degree of heritability has been also reported in longevity. Siblings of centenarians have an 8- to 17 -fold higher probability of living past the age of 100 years, accounting for only approximately 1 of 10000 individuals in the general population [14]. Several genes can affect HDL metabolism; among these are those related to cholesteryl ester transfer protein (CETP). A number of polymorphisms and rare variants in the human CETP gene have been identified. Two of the common polymorphisms, TaqIB and I405V, are associated with plasma HDL cholesterol levels [15-17].

In the current study, the prevalence of very high serum HDL cholesterol $(>70 \mathrm{mg} / \mathrm{dl})$, in at least 2 related members of a family plus a history of longevity (any living or deceased relative $>90$ years old) in the family are referred to as longevity syndrome (LS). The occurrence of LS is very rare. It is very likely that subjects with LS, besides high HDL cholesterol levels, have additional protective metabolic traits. Taking into account the National Cholesterol Education Pro- 
gram Adult Treatment Panel III (NCEP ATP III) guidelines for low-density lipoprotein (LDL) cholesterol levels [18, 19], the dilemma arises whether subjects with "raised" levels of LDL cholesterol but also with very high HDL concentration are still candidates for hypolipidaemic treatment. Gene polymorphisms could help decide whether individuals who have increased levels of both LDL cholesterol and HDL cholesterol require treatment. In line with previous work from our group [20], we tested the hypothesis that subjects with LS may carry the favorable variants of the CETP TaqIB or/and I405V polymorphisms compared with subjects not meeting the criteria for LS.

\section{MATERIALS AND METHODOLOGY}

\section{Study Population}

The study population consisted of 136 unrelated men and women without history of CHD. They were recruited from the Outpatient Lipid Clinic of our hospital (Athens, Greece) or self-referred (hospital personnel). All subjects were referred for moderate hypercholesterolaemia. In order to exclude underlying CHD the study population underwent a physical and a stress testing examination. A detailed family history was also obtained.

\section{LS Group}

Sixty nine probands of long-lived subjects met the following criteria for LS (LS group). The characterization of LS was based on ALL of the following criteria: 1) plasma fasting HDL cholesterol concentration $>70 \mathrm{mg} / \mathrm{dl}(1.79 \mathrm{mmol} / \mathrm{l})$, 2 ) at least 1 relative with plasma HDL cholesterol concentration $>70 \mathrm{mg} / \mathrm{dl}(1.79 \mathrm{mmol} / \mathrm{l}), 3)$ at least 1 relative (deceased or alive) over the age of 90 years old, and, 4) no personal or family history of cardiovascular disease.

\section{Non-LS Group}

Sixty seven subjects served as controls (non-LS group). They had desirable HDL cholesterol $(>40 \mathrm{mg} / \mathrm{dl}$ and $<70$ $\mathrm{mg} / \mathrm{dl} ;>1.03$ and $<1.79 \mathrm{mmol} / \mathrm{l})$, according to the NCEP ATP III guidelines [18, 19]. They did not have any relative (deceased or alive) with plasma HDL cholesterol $>70 \mathrm{mg} / \mathrm{dl}$ $(1.79 \mathrm{mmol} / \mathrm{l})$ nor any relative (deceased or alive) over the age of 90 years. This information was derived from the analysis of 3 generations.

Both LS and non-LS groups had no obesity, diabetes mellitus and hypertension which are risk factors for CHD. Additionally, they did not suffer from stroke, cancer, dementia or other age-related diseases. They were referred to our lipid clinic for their annual routine physical examination. The majority of individuals (88\%) from the LS group were referred to us for increased LDL cholesterol levels according to NCEP ATP III guidelines [18, 19]. The remained individuals were self-referred (hospital personnel) to the study for their exceptional high HDL levels. Heavy drinking, hepatic disease, renal disease, and hypothyroidism were among the exclusion criteria. Hypertension was defined as systolic arterial blood pressure $>140 \mathrm{mmHg}$ and/or diastolic blood pressure $>90 \mathrm{mmHg}$ or as current treatment with antihypertensive drugs. All subjects in both groups had a body mass index $(\mathrm{BMI})<30 \mathrm{~kg} / \mathrm{m}^{2}$. Diabetes was defined according to the diagnostic criteria of the World Health Organization or as current treatment of diabetes [21]. Only $15 \%$ of subjects were smokers in each group. None of the subjects was taking any medication. Triglycerides levels were $<150 \mathrm{mg} / \mathrm{dl}(1.68$ $\mathrm{mmol} / \mathrm{l})$ in both groups and mean LDL-cholesterol levels were $<130 \mathrm{mg} / \mathrm{dl}(3.3 \mathrm{mmol} / \mathrm{l})$ in non-LS group. These levels are normal according to the NCEP ATP III guidelines $[18,19]$. The mean value of LDL cholesterol in LS group was above $160 \mathrm{mg} / \mathrm{dl}$ (4 mmol/l), which is raised according to the NCEP ATP III guidelines [18, 19].

The Onassis Cardiac Surgery Center ethics committee approved the protocol of this study. All patients signed an informed consent form.

\section{Gene Polymorphisms}

CETP TaqIB and I405V genotyping was performed by polymerase chain reaction and restriction fragment length polymorphism as previously described [22-25].

\section{Biochemical Analyses}

Plasma total cholesterol, triglycerides and HDL cholesterol were measured using enzymatic colorimetric methods on a Roche Integra Biochemical analyzer with commercially available kits (Roche). The serum low density lipoprotein (LDL) levels were calculated using the Friedewald formula [26].

\section{Statistical Analysis}

The normality of continuous variables was tested using the Shapiro-Wilk statistic. None of the continuous variables had a non-normal distribution.

Continuous variables are presented as mean \pm standard deviation, while qualitative variables are presented as absolute and relative frequencies. Contingency tables were constructed to evaluate the association between genotypes, carriers and LS. The statistical evaluation for the categorical variables was based on the calculation of the chi-square and Fisher's exact criteria. Comparison of mean values between study groups was performed with the Student's t-test. Estimations of the multivariate association of the B2 allele with LS were performed by the calculation of the odds ratio (OR) and the corresponding confidence intervals through logistic regression analysis, after adjusting for age and BMI.

All tests were two-sided and p-values of 0.05 were considered significant. Data were analyzed using STATA ${ }^{\text {TM }}$ (version 9.0, Stata Corporation, College Station, TX, USA).

\section{RESULTS}

\section{Clinical and Laboratory Parameters}

Clinical characteristics and laboratory parameters of the non-LS and LS groups are shown in Table 1. BMI was lower in the LS compared with non-LS group. The mean age difference between the 2 groups was 6 years. Serum total LDL and HDL cholesterol were higher while plasma triglyceride concentration was lower in LS group compared with the non-LS group. Moreover the LDL/HDL cholesterol ratio was higher in the non-LS group and statistically significant in comparison with LS group. 


\section{Distribution of CETP Genotypes}

Table 2 shows the CETP genotype and allele frequencies in the 2 groups. No significant differences were found concerning the genotype frequency of TaqIB and I405V polymorphisms, between the 2 groups. However, the frequency of B2B2 genotype in LS group was twofold higher in comparison with the same genotype frequency in the non-LS group. The B2 allele frequency was significantly higher in the LS compared with the non-LS group, while B1 allele frequency was significantly higher in the non-LS compared with the LS group. Concerning the I and V alleles, there was a trend $(\mathrm{p}=0.053)$ with the latter being more frequent in the LS group. There was no significant correlation between the alleles of the TaqIB or I405V polymorphism and HDL levels with groups.

Those with LS had $69 \%$ more odds of having the B2 allele, compared with the non-LS, adjusting for age (Table
3). Although not significant, it should also be noted that the same participants had $64 \%$ more odds of having the B2 allele than the non-LS, adjusting for BMI (Table 3). When fully adjusted for BMI and age, there was not any statistically significant difference concerning the frequency of the B2 allele between LS and non-LS. When adjusted for triglycerides and age our result remained significant. When adjusted for the other lipids the significance was lost.

\section{DISCUSSION}

Our subjects with LS were more frequently carriers of the B2 allele of the TaqIB polymorphism than healthy subjects. The aim of the study was to evaluate whether subjects with LS in the family who potentially will live longer than the average life expectancy, have favourable CETP gene variants compared with healthy subjects. This genetic distinction may be important in the management of patients.

Table 1. Clinical Characteristics of the Non-LS and LS Group

\begin{tabular}{|c|c|c|c|c|c|}
\hline & Mean & SD & Mean & SD & $\mathbf{p}$ \\
\hline Age (years) & 56 & 13 & 49 & 20 & 0.008 \\
\hline BMI $\left(\mathrm{kg} / \mathrm{m}^{2}\right)$ & 26 & 4 & 23 & 3 & $<0.001$ \\
\hline $\mathrm{TG}(\mathrm{mg} / \mathrm{dl})$ & 93 & 34 & 81 & 36 & 0.043 \\
\hline HDL (mg/dl) & 53 & 13 & 84 & 12 & $<0.001^{*}$ \\
\hline LDL (mg/dl) & 128 & 27 & 168 & 45 & $<0.001$ \\
\hline LDL/HDL ratio & 2.6 & 0.8 & 2 & 0.6 & $<0.001$ \\
\hline
\end{tabular}

LS: longevity syndrome, BMI: body mass index, TC: total cholesterol, TG: triglycerides, HDL: high density lipoprotein cholesterol, LDL: low density lipoprotein cholesterol, SD: standard deviation.

${ }^{*}$ HDL was a criterion for the selection of patients.

To convert cholesterol from $\mathrm{mg} / \mathrm{dl}$ to $\mathrm{mmol} / \mathrm{l}$ divide by 38.67 and to convert triglycerides from $\mathrm{mg} / \mathrm{dl}$ to mmol/1 divide by 88.57 .

Table 2. Distribution of CETP Genotype and Allele Frequencies in the 2 Groups

\begin{tabular}{|c|c|c|c|}
\hline & Genotype or Allele & non-LS n (\%) & LS n (\%) \\
\hline \hline TaqIB & B2B2 & $13(19)$ & $26(38)$ \\
\hline & B1B2 & $36(54)$ & $31(45)$ \\
\hline & B1B1 & $17(25)$ & $12(17)$ \\
\hline & B1 ${ }^{a}$ & $70(53)$ & $55(40)$ \\
\hline & B2 $2^{\mathrm{a}}$ & $62(47)$ & $83(60)$ \\
\hline & VV & $1(2)$ & $5(7)$ \\
\hline & IV & $18(42)$ & $39(56)$ \\
\hline & II & $24(56)$ & $25(36)$ \\
\hline & V & $20(23)$ & $49(35)$ \\
\hline & I & $66(77)$ & $89(64)$ \\
\hline
\end{tabular}

CETP: cholesteryl ester transfer protein, LS: longevity syndrome. 
Table 3. Multiple Logistic Regression of LS on the B2 Allele, after Adjusting for BMI and Age

\begin{tabular}{|c|c|c|c|c|}
\hline Dependent Variable & Explanatory Variable & Odds Ratio & 95\% Confidence Interval & $\boldsymbol{p}$ \\
\hline \hline B2 allele $^{\mathrm{a}}$ & LS vs non-LS & 1.643 & $(0.968-2.789)$ & 0.07 \\
\hline B2 allele $^{\mathrm{b}}$ & LS vs non-LS & 1.687 & $(1.017-2.795)$ & 0.04 \\
\hline
\end{tabular}

LS: longevity syndrome, BMI: body mass index.

${ }^{\mathrm{a}}$ Adjusted for BMI, ${ }^{\mathrm{b}}$ adjusted for age

CETP may have pro- or anti-atherogenic properties depending upon the lipid-metabolic setting [27]. The HDL particle is influenced by CETP activity. CETP promotes the exchange of cholesteryl esters for triglycerides between HDL and triglyceride-rich lipoproteins [28] Furthermore, the HDL particle is involved in reverse cholesterol transport [29]. The cholesterol from extrahepatic cells is incorporated into the HDL particle and is transported to the liver [29]. Then, the excess cholesterol is removed via cholic acids to the intestine [29]. Low HDL levels $(<40 \mathrm{mg} / \mathrm{dl})$ are considered as an independent risk factor for CHD [2-7]. Ordovas et $a l$. suggested that increased HDL cholesterol levels resulting from lower CETP activity appear to be associated with a lower risk of CHD in male subjects [30].

There are controversial studies reporting that CETP polymorphisms can be associated with either increased CHD risk or longevity [31-35]. Also, significant associations of the B1B1 genotype with higher plasma CETP concentration and/or CETP activity and lower HDL cholesterol were found in several studies [30,36,37], but this is not consistently observed [38, 39]. In our study, we did not measure CETP activity, and we may only speculate that LS subjects had lower CETP concentration and activity since they had normal BMI [40] and normal triglyceride levels [41].

The West of Scotland Coronary Prevention Study tested the association of CETP polymorphisms with the risk of cardiovascular events [42]. In this study, those homozygous for the B2 allele had a 30\% reduced risk of a cardiovascular event (OR 0.70, CI (95) 0.51-0.96, $\mathrm{p}=0.03$ ) compared with B1 homozygotes. Furthermore, in a large population-based cohort, the B2 allele was associated with a less atherogenic LDL particle size distribution, consisting of decreased levels of the more atherogenic small LDL subfraction and increased levels of the less atherogenic large LDL [43-45]. In the Framingham Offspring Study, the B2 allele was associated with a reduced risk of CHD in men [30], and this was confirmed in the Veterans Affair HDL cholesterol Intervention Trial (VA HIT) [46]. In contrast, no association was found between any of the TaqIB genotypes and CHD in subjects with a history of myocardial infarction in the Coronary and Recurrent Events Study [47] and in a cohort of healthy middle-aged U.S. physicians [48]. Brousseau et al. [46] reported that in men with CHD and HDL deficiency (VA HIT study), the frequency of the B2B2 genotype was reduced. However, there are studies suggesting that B2 allele carriers have higher HDL cholesterol levels than B1 allele carriers; paradoxically they have an increased risk for CHD [49, 50, 22]. However, a meta-analysis of 7 studies (Physicians' Health Study, Northwick Park Heart Study, Reykjavik, ECTIM, OPERA, EARS and the study of Arca et al), reported a lower cardiovascular risk in B2 compared with B1 homozygotes [37].

A possible mechanism that explains the association of CETP genotype with CHD risk is the influence on plasma HDL. Kuivenhoven et al. [51] reported a strong association between B1 allele and low HDL cholesterol levels, which is in agreement with the results of others [36, 52, 53]. Moreover, our group reported a positive association between B1 genotype and postprandial lipemia [20]. Bruce et al. reported that the HDL cholesterol levels were higher in VV than IV and II men [54]. However, the increase in HDL cholesterol was only significant in VV men with plasma triglyceride $>165 \mathrm{mg} / \mathrm{dl}(1.85 \mathrm{mmol} / \mathrm{l})$. In another study, the individuals homozygous for the $\mathrm{V}$ allele also had the highest HDL cholesterol levels [55]. Opposite to the beneficial influence of homozygosity of VV, Kakko et al., found that the VV genotype seems to be most harmful for men with the highest alcohol consumption [56]. In our study, the lack of an association between the TaqIB or I405V polymorphisms and HDL cholesterol observed within groups does not weaken the association between these polymorphisms and the presence of the LS. This was expected since each group was selected to have normal or very high HDL levels whose range was narrow. Therefore, analysis with a larger number of subjects is needed in order to assess such an association.

Populations with low CHD mortality rates, for example Eskimos, have high levels of HDL cholesterol (even with conjointly elevated LDL) which is similar to our study population [57]. Additionally, subjects with familial hypobeta and familial hyperalphalipoproteinaemia which are also associated with lower CHD rates, share a common characteristic, a ratio of LDL:HDL of approximately $1: 1$. This ratio of LDL:HDL is considerably lower than the usual 2.5:1 observed in the general population [58]. In our LS group, the ratio was 2:1 and in non-LS group 2.7:1 which is comparable with other studies [20].

The limitations in our study are the mean age difference ( 6 years) and the different BMI between the 2 groups. Although significant, these factors can not influence the gene distribution of our study population. The small number of our sample and the differences in lipid levels are disadvantages. When adjusted for triglycerides and age the statistical significance of our results remained. When adjusted for the other lipids there was not statistical significance concerning the B2 allele between LS and non-LS groups. However hyper-HDL-cholesterolemia and longevity represent various pathophysiological conditions and can not be represented solely from the genetic constitution of an organism, nor solely from the environmental factors. Additionally, our sample although small, was not genetically heterogeneous, 
more specifically there was no population admixture, something that in past created inconsistencies to similar genetic association studies. Considering the existence of a strong familial component to extreme longevity, and the fact that previous studies investigated longevity in families [59] or in a preselected population, it was not possible to find a completely age-matched control group. For example, siblings of centenarians have an 8- to 17-fold higher probability of living past the age of 100 years, accounting for only approximately 1 of 10000 individuals in the general population [60].

In our study, LS subjects had higher B2 allele frequency and lower triglyceride levels compared with the non-LS group. In the LS group, total and LDL cholesterol levels were higher compared with non-LS individuals. Thus, the dilemma arises whether or not LS subjects should/should not receive hypolipidaemic treatment according to available guidelines. Until more knowledge is available the management of these individuals remains controversial. Some of the prerequisites could include that subjects with LS should not only have very high levels of HDL cholesterol but also favorable gene polymorphisms. However, further investigations with a larger sample and including other gene polymorphisms, are needed. Obviously, prospective studies in patients with LS have their limitations.

\section{CONCLUSION}

Individuals with LS had a higher B2 allele frequency of the TaqIB polymorphism than non-LS subjects. Gene polymorphisms could help decide whether individuals who have increased levels of both LDL cholesterol and HDL cholesterol require treatment.

\section{DECLARATION OF INTEREST}

This study was conducted independently; no company or institution supported it financially. Some of the authors have given talks, attended conferences and participated in trials and advisory boards sponsored by various pharmaceutical companies.

$\begin{array}{lll}\text { ABBREVIATIONS } \\ \mathrm{BMI} & =\text { Body mass index } \\ \mathrm{CETP} & = & \text { Cholesteryl ester transfer protein } \\ \mathrm{CHD} & = & \text { Coronary heart disease } \\ \mathrm{HDL} & = & \text { High density lipoprotein } \\ \mathrm{LDL} & = & \text { Low density lipoprotein } \\ \mathrm{LS} & = & \text { Longevity syndrome } \\ \mathrm{OR} & = & \text { Odds ratio }\end{array}$

\section{REFERENCES}

[1] Barr DP, Russ EM, Eder HA. Protein-lipid relationships in human plasma. Am J Med 1951; 11: 480-5.

[2] Yaari S, Goldbourt, Even-Zohar S, Neufeld HN. Associations of serum high density lipoprotein and total cholesterol with total, cardiovascular, and cancer mortality in a 7-year prospective study of 10000 men. Lancet 1981; 1: 1011-5.

[3] Gordon DJ, Probstfield JL, Garrison RJ, et al. High-density lipoprotein cholesterol and cardiovascular disease. Four prospective American studies. Circulation 1989; 79: 8-15.
[4] Gofman JW, Young W, Tandy R. Ischemic heart disease, atherosclerosis, and longevity. Circulation 1966; 34: 679-97.

[5] Turner RC, Millns H, Neil HA, et al. Risk factors for coronary artery disease in non-insulin dependent diabetes mellitus: United Kingdom Prospective Diabetes Study (UKPDS:23). BMJ 1998; 316: 823-8.

[6] Assmann G, Schulte H. Relation of high-density lipoprotein cholesterol and triglycerides to incidence of atherosclerotic coronary artery disease (the PROCAM experience). Prospective Cardiovascular Munster Study. Am J Cardiol 1992; 70: 733-7.

[7] Castelli WP, Garrison RJ, Wilson PW, Abbott RD, Kalousdian S, Kannel WB. Incidence of coronary heart disease and lipoprotein cholesterol levels. The Framingham Study. JAMA 1986; 256: 28358.

[8] Packard C, Saito Y. Non-HDL cholesterol as a measure of atherosclerotic risk. J Atheroscler Thromb 2004; 11: 6-14.

[9] Nagano M, Yamashita S, Hirano K, et al. Molecular mechanisms of cholesteryl ester transfer protein deficiency in Japanese. J Atheroscler Thromb 2004; 11: 110-21.

[10] Arai Y, Hirose N. Aging and HDL metabolism in elderly people more than 100 years old. J Atheroscler Thromb 2004; 11: 246-52.

[11] Nikkilä M, Heikkinen J. Age Ageing 1990; 19: 119-24.

[12] Hunt SC, Hasstedt SJ, Kuida H, Stults BM, Hopkins PN, Williams RR. Genetic heritability and common environmental components of resting and stressed blood pressures, lipids, and body mass index in Utah pedigrees and twins. Am J Epidemiol 1989; 129: 625-38.

[13] Snieder H, van Doornen LJ, Boomsma DI. The age dependency of gene expression for plasma lipids, lipoproteins, and apolipoproteins. Am J Hum Genet 1997; 60: 638-50.

[14] Barzilai N, Atzmon G, Schechter C, et al. Unique lipoprotein phenotype and genotype associated with exceptional longevity. JAMA 2003; 290: 2030-40.

[15] Thompson A, Di Angelantonio E, Sarwar N, et al. Association of cholesteryl ester transfer protein genotypes with CETP mass and activity, lipid levels, and coronary risk. JAMA 2008; 299: 2777-88.

[16] Boekholdt SM, Thompson JF. Natural genetic variation as a tool in understanding the role of CETP in lipid levels and disease. J Lipid Res 2003; 44: 1080-93.

[17] Boekholdt SM, Kuivenhoven JA, Hovingh GK, Jukema JW, Kastelein JJ, van Tol A. CETP gene variation: relation to lipid parameters and cardiovascular risk. Curr Opin Lipidol 2004; 15: 3938.

[18] Expert Panel on Detection, Evaluation, and Treatment of High Blood Cholesterol in Adults. Executive Summary of the Third Report of the National Cholesterol Education Program (NCEP) Expert Panel on Detection, Evaluation, and Treatment of High Blood Cholesterol in Adults (Adult Treatment Panel III). JAMA 2001; 285: 2486-97.

[19] National Cholesterol Education Program (NCEP) Expert Panel on Detection, Evaluation, and Treatment of High Blood Cholesterol in Adults (Adult Treatment Panel III). Third Report of the National Cholesterol Education Program (NCEP) Expert Panel on Detection, Evaluation, and Treatment of High Blood Cholesterol in Adults (Adult Treatment Panel III) final report. Circulation 2002; 106: 3143421.

[20] Kolovou GD, Anagnostopoulou KK, Salpea KD, et al. Postprandial lipemia in postmenopausal women with high fasting high-density lipoprotein cholesterol. Am J Med Sci 2006; 331(1): 10-6.

[21] Alberti KG, Zimmet PZ. Definition, diagnosis and classification of diabetes mellitus and its complications. Part 1: diagnosis and classification of diabetes mellitus provisional report of a WHO consultation. Diabet Med 1998; 15: 539-53.

[22] Kolovou G, Anagnostopoulou K, Kostakou P, et al. Association between the TaqIB polymorphism in the cholesteryl ester transfer protein gene locus and postprandial plasma lipoprotein levels in heterozygotes for familial hypercholesterolemia. Clin Chem Lab Med 2007; 45: 1190-8.

[23] Fumeron F, Betoulle D, Luc G, et al. Alcohol intake modulates the effect of a polymorphism of the cholesteryl ester transfer protein gene on plasma high density lipoprotein and the risk of myocardial infarction. J Clin Invest 1995; 96: 1664-71.

[24] Gudnason V, Kakko S, Nicaud V, et al. Cholesteryl ester transfer protein gene effect on CETP activity and plasma high-density lipoprotein in European populations. The EARS Group. Eur J Clin Invest 1999; 29: 116-28.

[25] Kolovou GD, Anagnostopoulou KK, Karyofillis P, et al. Cholesteryl ester transfer protein gene polymorphisms and severity of coronary stenosis. Clin Invest Med 2006; 29: 14-9. 
[26] Friedewald WT, Levy RI, Fredrickson DS. Estimation of the concentration of the low-density lipoprotein cholesterol in plasma, without use of the preparative ultracentrifuge. Clin Chem 1972; 18: 499-502.

[27] Tsai MY, Li N, Sharrett AR, et al. Associations of genetic variants in ATP-binding cassette A1 and cholesteryl ester transfer protein and differences in lipoprotein subclasses in the multi-ethnic study of atherosclerosis. Clin Chem 2009; 55: 481-8.

[28] Kolovou GD, Anagnostopoulou KK, Daskalopoulou SS, Mikhailidis DP, Cokkinos DV. Clinical relevance of postprandial lipemia. Curr Med Chem 2005; 12: 1931-45.

[29] Lewis GF, Rader DJ. New insights into the regulation of HDL metabolism and reverse cholesterol transport. Circ Res 2005; 96: 122132 .

[30] Ordovas JM, Cupples LA, Corella D, et al. Association of cholesteryl ester transfer protein-TaqIB polymorphism with variations in lipoprotein subclasses and coronary heart disease risk: the Framingham study. Arterioscler Thromb Vasc Biol 2000; 20: 1323-9.

[31] Koizumi J, Mabuchi H, Yoshimura A, et al. Deficiency of serum cholesteryl-ester transfer activity in patients with familial hyperalphalipoproteinaemia. Atherosclerosis 1985; 58:175-86.

[32] Inazu A, Brown ML, Hesler CB, et al. Increased high-density lipoprotein levels caused by a common cholesteryl-ester transfer protein gene mutation. N Engl J Med 1990; 323: 1234-8.

[33] Hirano K, Yamashita S, Nakajima N, et al. Genetic cholesteryl ester transfer protein deficiency is extremely frequent in the Omagari area of Japan; marked hyperalphalipoproteinemia caused by CETP gene mutation is not associated with longevity. Arterioscler Thromb Vasc Biol 1997; 17: 1053-9.

[34] Zhong S, Sharp DS, Grove JS, et al. Increased coronary heart disease in Japanese-American men with mutation in the cholesteryl ester transfer protein gene despite increased HDL levels. J Clin Invest 1996; 97: 2917-23.

[35] Hirano K, Yamashita S, Sakai N, et al. Molecular defect and atherogenicity in cholesteryl ester transfer protein deficiency. Ann N Y Acad Sci 1995; 748: 599-602.

[36] Kuivenhoven JA, Jukema JW, Zwinderman AH, et al. The role of a common variant of the cholesteryl ester transfer protein gene in the progression of coronary atherosclerosis. The Regression Growth Evaluation Statin Study Group. N Engl J Med 1998; 338: 86-93.

[37] Boekholdt SM, Sacks FM, Jukema JW, et al. Cholesteryl ester transfer protein TaqIB variant, high-density lipoprotein cholesterol levels, cardiovascular risk, and efficacy of pravastatin treatment: individual patient meta-analysis of 13,677 subjects. Circulation 2005; 111: 27887.

[38] Freeman DJ, Griffin BA, Holmes AP, et al. Regulation of plasma HDL cholesterol and subfraction distribution by genetic and environmental factors: associations between the TaqI B RFLP in the CETP gene and smoking and obesity. Arterioscler Thromb 1994; 14: 336-44.

[39] Goto A, Sasai K, Suzuki S, et al. Cholesteryl ester transfer protein and atherosclerosis in Japanese subjects: a study based on coronary angiography. Atherosclerosis 2001; 159: 153-63.

[40] Arai T, Yamashita S, Hirano K, et al. Increased plasma cholesteryl ester transfer protein in obese subjects. A possible mechanism for the reduction of serum HDL cholesterol levels in obesity. Arterioscler Thromb 1994; 14: 1129-36.

[41] Tato F, Vega GL, Grundy SM. Determinants of plasma HDLcholesterol in hypertriglyceridemic patients. Role of cholesterol-ester transfer protein and lecithin cholesteryl acyl transferase. Arterioscler Thromb Vasc Biol 1997; 17: 56-63.

[42] Freeman DJ, Samani NJ, Wilson V, et al. A polymorphism of the cholesteryl ester transfer protein gene predicts cardiovascular events in non-smokers in the West of Scotland Coronary Prevention Study. Eur Heart J 2003; 24: 1833-42.

[43] Brunzell JD, Hokanson JE. Low-density and high-density lipoprotein subspecies and risk for premature coronary artery disease. Am J Med 1999; 107 (Supp1 2A): 16-8.
[44] Stampfer MJ, Krauss RM, Ma J, et al. A prospective study of triglycerides, low-density lipoprotein particle diameter, and risk of myocardial infarction. JAMA 1996; 276: 882-8.

[45] Gardner CD, Fortmann SP, Krauss RM. Association of small lowdensity lipoprotein particles with the incidence of coronary artery disease in men and women. JAMA 1996; 276: 875-81.

[46] Brousseau ME, O'Connor JJ Jr, Ordovas JM, et al. Cholesteryl ester transfer protein TaqI B2B2 genotype is associated with higher HDL cholesterol levels and lower risk of coronary heart disease end points in men with HDL deficiency: Veterans Affairs HDL Cholesterol Intervention Trial. Arterioscler Thromb Vasc Biol 2002; 22: 114854.

[47] de Grooth GJ, Zerba KE, Huang S, et al. The cholesteryl ester transfer protein (CETP) TaqIB polymorphism in the Cholesterol and Recurrent Events study (CARE): no interaction with the response to pravastatin therapy and no effects on cardiovascular outcome. J Am Coll Cardiol 2004; 43: 854-7.

[48] Liu S, Schmitz C, Stampfer MJ, et al. A prospective study of TaqIB polymorphism in the gene coding for cholesteryl ester transfer protein and risk of myocardial infarction in middle-aged men. Atherosclerosis $2002 ; 161: 469-74$.

[49] Borggreve SE, Hillege HL, Wolffenbuttel BH, et al. An increased coronary risk is paradoxically associated with common cholesteryl ester transfer protein gene variations that relate to higher high-density lipoprotein cholesterol: a population-based study. J Clin Endocrinol Metab 2006; 91: 3382-8.

[50] Blankenberg S, Rupprecht HJ, Bickel C, et al. Common genetic variation of the cholesteryl ester transfer protein gene strongly predicts future cardiovascular death in patients with coronary artery disease. J Am Coll Cardiol 2003; 41: 1983-9.

[51] Kuivenhoven JA, de Knijff P, Boer JM, et al. Heterogeneity at the CETP gene locus. Influence on plasma CETP concentrations and HDL cholesterol levels. Arterioscler Thromb Vasc Biol 1997; 17: 560-8.

[52] Kondo I, Berg K, Drayna D, Lawn R. DNA polymorphism at the locus for human cholesteryl ester transfer protein (CETP) is associated with high density lipoprotein cholesterol and apolipoprotein levels. Clin Genet 1989; 35: 49-56.

[53] Mitchell RJ, Earl L, Williams J, Bisucci T, Gasiamis H. Polymorphisms of the gene coding for the cholesteryl ester transfer protein and plasma lipid levels in Italian and Greek migrants to Australia. Hum Biol 1994; 66: 13-25.

[54] Bruce C, Sharp DS, Tall AR. Relationship of HDL and coronary heart disease to a common amino acid polymorphism in the cholesteryl ester transfer protein in men with and without hypertriglyceridemia. J Lipid Res 1998; 39: 1071-8.

[55] Gudnason V, Thormar K, Humphries SE. Interaction of the cholesteryl ester transfer protein $\mathrm{I} 405 \mathrm{~V}$ polymorphism with alcohol consumption in smoking and non-smoking healthy men, and the effect on plasma HDL cholesterol and apoAI concentration. Clin Genet 1997; 51: 15-21.

[56] Kakko S, Tamminen M, Päivänsalo $\mathrm{M}$, et al. Cholesteryl ester transfer protein gene polymorphisms are associated with carotid atherosclerosis in men. Eur J Clin Invest 2000; 30: 18-25.

[57] Bang HO, Dyerberg J, Nielsen AB. Plasma lipid and lipoprotein pattern in Greenlandic West-Coast Eskimos. Lancet 1971; 1: 11435.

[58] Glueck CJ, Gartside P, Fallat RW, Sielski J, Steiner PM. Longevity syndromes: Familial hypobeta and familial hyperalpha lipoproteinemia. J Lab Clin Med 1976; 88: 941-57.

[59] Puca AA, Daly MJ, Brewster SJ, et al. A genome-wide scan for linkage to human exceptional longevity identifies a locus on chromosome 4. Proc Natl Acad Sci USA 2001 Aug 28; 98: 10505-8.

[60] Barzilai N, Atzmon G, Schechter C, Schaefer EJ, Cupples AL, Lipton $\mathrm{R}$, Cheng S, Shuldiner AR. Unique lipoprotein phenotype and genotype associated with exceptional longevity. JAMA 2003; 290: 203040 . 